\title{
Structural definition of a novel CD4-induced epitope that is targeted by a single-headed immunoglobulin to effect broad and potent HIV neutralization
}

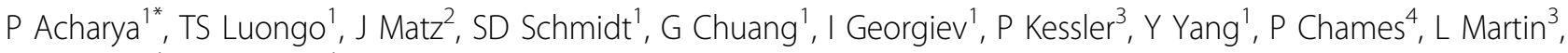 \\ JR Mascola', PD Kwong ${ }^{1}$
}

From AIDS Vaccine 2012

Boston, MA, USA. 9-12 September 2012

\section{Background}

HIV-1 enters cells by sequentially binding the CD4 receptor and a coreceptor, either CCR5 or CXCR4. Functional constraints result in a high degree of conservation of the receptor-binding sites making them potential targets for intervention. The coreceptor-binding site on HIV-1 envelope gp120 glycoprotein is protected from the humoral immune system by conformational masking and steric occlusion. The site becomes available after a conformational change in gp120 following CD4 engagement, but at that point in the entry process, the proximity of the viral and cellular membranes makes the site inaccessible to bulky antibody molecules. Thus, in spite of being highly conserved, this region has not been considered a viable vaccine target.

\section{Methods}

Single domain antibody vHH120.4 was isolated from llama immunized with gp120 covalently linked to a CD4mimetic peptide. Full-length versions of this antibody (IgG2B and IgG3) were created and tested for neutralization. The structure of vHH120.4 bound to gp120 from the HIV-1 YU2 strain was determined at $2.1 \AA$ resolution.

\section{Results}

Both IgG2B and IgG3 versions of the vHH120.4 potently neutralized over $95 \%$ of a panel of circulating Tier 2 HIV-1 isolates. Structural analyses of vHH120.4 bound to gp120 revealed a novel CD4i epitope that involves antibody interactions with region on gp120 encompassing the bridging sheet and the base of the V3 loop, the $\beta 19$ strand, the CD4-binding loop, and the glycan at Asn 386 . This epitope overlaps the classically defined CD4-induced epitopes recognized by antibodies $17 \mathrm{~b}$ and $48 \mathrm{~d}$, but is shifted towards the site of CD4 attachment.

\section{Conclusion}

The discovery of a neutralizing CD4-induced epitope indicates that not all CD4-induced sites are masked from neutralization. Whether human antibodies can also utilize the newly defined vHH120.4 epitope for effective neutralization remains to be determined; HIV-1 envelope probes designed to specifically select antibodies targeting this epitope are now being developed.

\section{Author details}

${ }^{1}$ National Institutes of Health, Bethesda, MD, USA. ${ }^{2}$ Inserm, Marseille, France. ${ }^{3}$ CEA/iBiTecs, Gif sur Yvette, France. ${ }^{4}$ INSERM, Marseille, France.

Published: 13 September 2012

doi:10.1186/1742-4690-9-S2-P346

Cite this article as: Acharya et al: Structural definition of a novel CD4induced epitope that is targeted by a single-headed immunoglobulin to effect broad and potent HIV neutralization. Retrovirology 2012 9(Suppl 2):P346.

${ }^{1}$ National Institutes of Health, Bethesda, MD, USA

Full list of author information is available at the end of the article

(c) 2012 Acharya et al; licensee BioMed Central Ltd. This is an Open Access article distributed under the terms of the Creative Commons Attribution License (http://creativecommons.org/licenses/by/2.0), which permits unrestricted use, distribution, and reproduction in any medium, provided the original work is properly cited. 